\title{
Presence of professional stress in teaching staff at the Medical faculty in Foca
}

\author{
Milica Vuksanović, Dragica Marić, Jelena Pavlović, \\ Sandra Joković, Natalija Hadživuković \\ University of Sarajevo, Faculty of Medicine, Studentska 5, 73300 Foca, \\ Republic of Srpska, Bosnia and Herzegovina \\ vuksanovicmilica24@icloud.com; maricevall@yahoo.com; pjelena55I@gmail.com; \\ sandra.jokovic@hotmail.com; natalijahadzivukovic@yahoo.com
}

\begin{abstract}
Introduction: In recent years, an increasing number of studies deal with the study of the psychosocial aspects of the working-age population. The aim of the research was to examine the level of professional stress in the teaching staff at the Medical Faculty in Foca.

Methodology: The study was designed as a cross-sectional study with 47 workers. The survey included faculty members from the Medical Faculty in Foca. We used a sociodemographic questionnaire, a questionnaire to assess health status and Maslach burnout inventory. Statistical analysis was performed with the use of SPSS statistical software package. Results: Most respondents (83\%) are under stress, and $42.6 \%$ of the respondents identified symptoms of work related burnout. Physical and mental component of quality of life was assessed as "bad" by $2.1 \%$ respondents; their physical and mental health was rated as "well" by $23.4 \%$, and by $74.5 \%$ respondents was rated as excellent. Conclusion: Those respondents that rated the presence of burnout symptoms rated also their quality of mental health as lower.

Keywords: quality of life, professional stress, health.
\end{abstract}

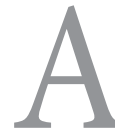

$\mathrm{t}$ the present time the concept of stress is widely used, both in science and in everyday life. There are many definitions of stress dealing with aspects of stress, which are important for the scientific discipline from where they came from, and that immediately indicates the width and importance of this problem. Stress is present in different spheres of human life; there are different patterns and individual consequences (Tennat, 2001). Numerous empirical studies show that the sources of stress on work are many, and that the stress related to work frequently occurs. The most common causes of workplace stress are: lack of control, poor working conditions, too much re- 
sponsibility, disturbed interpersonal relationships, type of work, tasks that are performed in shifts and those jobs that require extended working hours. The frequency of impacts of negative stress on health and physical disorders goes from $50-70 \%$ of the total number of pathogens. There is virtually no area of human activity that is not related to stress and stressful situations. A number of medical experts (Nyssen, et al., 2003) stated that stress plays a major role in the causation of various degenerative diseases such as high blood pressure, heart disease, metabolic disorder and decline in immune capacity of the body. It is very important to develop strategies to control stress, which help to cope with stressful situations and to recognize the situation that the individual cannot influence on (Jackson, 1999).The objective of the research was to examine the level of professional stress of the teaching staff at the Medical Faculty in Foca.

\section{Methods}

The study was designed as a cross-sectional study with 47 respondents, of which $14.9 \%$ men and $85.1 \%$ women, aged $43.14 \pm 9.46$ years. The survey included the teaching staff from the Medical Faculty in Foca during the period from February to June 2016. The criteria for inclusion in the study were: respondents who work and are directly involved in the care and treatment of patients. Criteria for exclusion from the study were: respondents who are not involved in the care and treatment of patients and subjects who did not respond to five or more questions or have marked the same answers to all the questions. The study included the following instruments: sociodemographic questionnaire, the questionnaire for the assessment of the state of health (Short Form 36 Health Survey-SF-36) (Ware, 1993) and Maslach Burnout Inventory (MBI) (Maslach et al., 1996). The sociodemographic questionnaire was created for the purpose of this research and contains 10 questions related to the characteristics of the respondents (gender, age, marital status, place of residence, family income, degree of education of respondents).

Maslach Burnout Inventory - The MBI has three structural units and measures the following dimensions: a feeling of emotional exhaustion and overwork, depersonalization, or a sense of discomfort caused by effort and a sense of competence and job satisfaction. The test consists of 22 claims that are scored in seven categories from o to 6 (o - never, 1 - several times a year or less, 2 - once a month or less, 3 - several times a month, 4 - once a week, 5 - several times a week, 6 - every day).The Subscale of Emotional Exhaustion (EE) consists of 9 items, the Subscale of Depersonalization (DP) consists of 5 , and 8 items make the subscale of personal fulfilment with job (PA). If the value on test 51 for EE is greater than 26, there is a high risk of burnout syndrome, and / or if the value for the DP test is higher than 9, there is also a high risk of burnout syndrome. A value of less or equal to 18 on the subscale EE represent a small burnout risk, and a value from 19 to 26 is a medium burnout risk. As for the PA subscale, the low burnout risk is greater or equal than 40 , the mid risk is from 39 to 34 , and the high burnout risk is less or equal to 33 , but the general conclu- 
sion about the presence of burnout syndrome can't be obtained by observing the PA subscale like isolated case. The subscale PA is relevant only if it is confirmed with an EE or DP scale. The total score is possible in the range o -132 . MBI has three structural units and measures the following dimensions: a feeling of emotional exhaustion and pretensioning job, depersonalization or discomfort caused by exertion and a sense of competition and job satisfaction.

Statistical analysis was performed using SPSS 24.0 statistical software package. Of the non-parametric statistical tests we used $\chi^{2}$ - square test. The correlation is performed using the Pearson correlation coefficient. As the level of statistical significance of differences, its been used a common value of $\mathrm{p}<0.05$. For displaying the average values we used the arithmetic mean and standard-deviation. The data are presented in tables and charts.

\section{Results}

In shifts works $46.8 \%$ of respondents and majority (83\%) is exposed to stress at work. Professional burnout syndrome was observed in $42.6 \%$ of workers, middle and high level of emotional exhaustion was observed in 57.5\%, depersonalization was observed in $44.7 \%$, while the low and middle level of personal achievements are observed in $61.7 \%$ of the respondents. Using the SF-36 questionnaire that evaluates a common component of physical health, it has been observed that the high level of the Physical Component Summary (PCS)is present in $74.5 \%$, of respondents middle level in $23.5 \%$, whereas the low level is observed in only $\mathbf{2 . 1 \%}$ Between groups of respondents with different level of PCS highly statistically significant difference was observed $\left(\chi_{2}=20,228 ; p=0.001\right)$ comparing to level of emotional exhaustion. Statistically significant number of respondents with high level of PCS (36.2\%) was observed comparing to respondents with low level of PCS (o\%) (table 1).

In $74.4 \%$ of respondents registered a high level of common mental health components, $23.4 \%$ showed a medium level, while only one respondent showed low levels of MCS. Between groups of subjects with different levels of MCS there was a high significant difference compared to the level of emotional exhaustion ( $\left.\chi_{2}=15.276 ; \mathrm{p}=0.004\right)$ and a statistically significant difference compared to the level of depersonalization $\left(\chi^{2}=11,358\right.$; $\left.p=0.023\right)$, wherein $40.4 \%$ of subjects who have a high level of MCS and shows no signs of emotional exhaustion, while $55.3 \%$ of patients with a high level of MCS and shows no signs of depersonalization. Table 2 shows the differences in the average values of the domains of the SF-36 questionnaire for the presence of a professional burnout syndrome. A statistically highly significant difference was observed with respect to domain limitations due to emotional problems $(t=-3.563, p=0.002)$, where the average value of this domain in respondents with present burnout syndromes is significantly lower $(66,60 \pm 41,92)$, compared to the scoring state levels of patients where it is not detected burning syndrome (100.00 \pm 0.001$)$. Social functioning is at statistically significantly higher level $(\mathrm{t}=-2.019, \mathrm{p}=$ $0.050)$ in the patients without the present syndrome $(87.03 \pm 13.19)$ compared 
to those with the present burnout syndrome $(78.65 \pm 15.21)$ while differences in relation to domains of physical functioning, vitality, mental health, general health, body pains and limitations due to physical health were not found.

Table 1: Emotional exhaustion, depersonalization, personal success and a total score of MBI in regard to the levels of physical health (PCS).

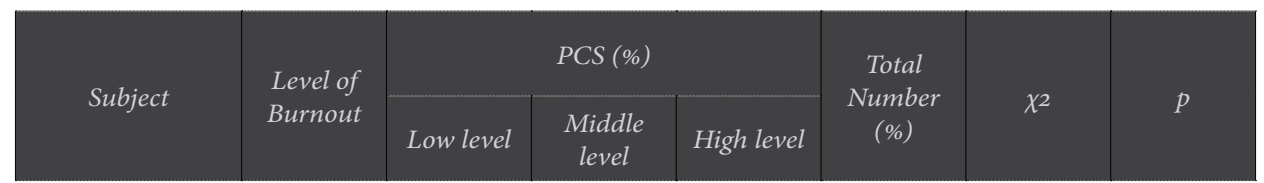

\begin{tabular}{|c|c|c|c|c|c|c|c|}
\hline \multirow{3}{*}{$\begin{array}{l}\text { Emotional ex- } \\
\text { haustion (De- } \\
\text { pressive anxious } \\
\text { syndrome) }\end{array}$} & Low level & o (o) & $3(6.4)$ & $17(36.2)$ & $20(42.6)$ & \multirow{3}{*}{20.228} & \multirow{3}{*}{0.001} \\
\hline & $\begin{array}{l}\text { Middle } \\
\text { level }\end{array}$ & o (o) & $6(12.8)$ & $18(38.3)$ & $24(51.1)$ & & \\
\hline & High level & $1(1.2)$ & $2(4 \cdot 3)$ & $o(0)$ & $3(64)$ & & \\
\hline \multirow{3}{*}{$\begin{array}{l}\text { Depersonaliza- } \\
\text { tion (Lack of em- } \\
\text { pathy) }\end{array}$} & Low level & o (o) & $7(14,9)$ & $19(40,4)$ & $26(55,3)$ & \multirow{3}{*}{9,419} & \multirow{3}{*}{0,051} \\
\hline & $\begin{array}{l}\text { Middle } \\
\text { level }\end{array}$ & $1(2.1)$ & $o(0)$ & $12(25,5)$ & $13(27,7)$ & & \\
\hline & High level & o (o) & $4(8,5)$ & $4(8,5)$ & $8(17,0)$ & & \\
\hline \multirow{3}{*}{$\begin{array}{l}\text { Personal success } \\
\text { (Achievement) }\end{array}$} & Low level & $1(2,1)$ & $7(14,9)$ & $17(36,2)$ & $25(53,2)$ & \multirow{3}{*}{1,790} & \multirow{3}{*}{0,774} \\
\hline & $\begin{array}{l}\text { Middle } \\
\text { level }\end{array}$ & o (o) & $1(2,1)$ & $3(6,4)$ & $4(8,5)$ & & \\
\hline & High level & o (o) & $3(6,4)$ & $15(31,9)$ & $18(38,3)$ & & \\
\hline \multirow{2}{*}{$\begin{array}{l}\text { Burn-out syn- } \\
\text { drome measured } \\
\text { using MBI scales }\end{array}$} & $\begin{array}{l}\text { With } \\
\text { burnout } \\
\text { syndrome }\end{array}$ & $1(2,1)$ & $5(10,6)$ & $14(29,8)$ & $20(42,6)$ & \multirow{2}{*}{1,481} & \multirow{2}{*}{0,477} \\
\hline & $\begin{array}{l}\text { Without } \\
\text { burnout } \\
\text { syndrome }\end{array}$ & o (o) & $6(12,8)$ & $21(44,7)$ & $27(57,4)$ & & \\
\hline
\end{tabular}


Tabel 2: The arithmetic means and standard deviation of the domains of the SF-36 questionnaire according to the presence of burnout syndrome.

\begin{tabular}{|c|c|c|c|c|}
\hline \multirow{2}{*}{$\begin{array}{c}\text { Domains of the SF- } \\
36 \text { questionnaire }\end{array}$} & \multicolumn{2}{|c|}{ MBI Mean (SD) } & \multirow{2}{*}{$t$} & \multirow{2}{*}{$p$} \\
\hline & With burnout syndrome & Without burnout syndrome & & \\
\hline $\begin{array}{l}\text { Physical func- } \\
\text { tioning }\end{array}$ & $87,75(13,71)$ & $83,51(18,23)$ & 0,871 & 0,389 \\
\hline $\begin{array}{l}\text { Limitations due to } \\
\text { physical health }\end{array}$ & $78,75(34,67)$ & $91,66(16,98)$ & $-1,535$ & 0,137 \\
\hline $\begin{array}{l}\text { Limitations due to } \\
\text { emotional prob- } \\
\text { lems }\end{array}$ & $66,60(41,92)$ & $100,00(0,001)$ & $-3,563$ & 0,002 \\
\hline Vitality & $60,75(12,59)$ & $65,18(9,75)$ & $-1,361$ & 0,180 \\
\hline Mental health & $50,65(9,46)$ & $47,70(5,53)$ & 1,340 & 0,187 \\
\hline Social functioning & $78,65(12,21)$ & $87,03(13,19)$ & $-2,019$ & 0,050 \\
\hline Physical pains & $42,25(9,52)$ & $46,14(8,16)$ & $-1,507$ & 0,139 \\
\hline General health & $68,25(14,44)$ & $69,07(16,67)$ & $-0,192$ & 0,849 \\
\hline MCS & $64,04(12,65)$ & $74,05(5,63)$ & $-3,660$ & 0,003 \\
\hline PCS & $69,11(12,52)$ & $73,46(8,47)$ & $-1,420$ & 0,162 \\
\hline
\end{tabular}

Pearson correlation coefficient show that there is a statistically highly significant positive correlation $(\mathrm{r}=0.391 ; \mathrm{p}=0.007)$ between the professional burnout syndrome and age, where older persons are more exposed to a professional burnout syndrome. The elderly are also significantly more exposed to depersonalization $(\mathrm{r}=-0.321 ; \mathrm{p}=0.028)$, while younger people are in positive correlation with personal achievement and satisfaction $(\mathrm{r}=-0.454 ; \mathrm{p}=0.001)$. Younger people have a higher quality of mental and physical health, but this positive correlation is not statistically significant. Statistically significant positive correlation was observed regarding the relation of years of service and MBI score $(\mathrm{r}=0.377 ; \mathrm{p}=0.009)$, where the subjects with higher values of years of service, have a higher value of MBI. High significant negative correlation was observed between the years of service and personal satisfaction $(r=-0.395 ; \mathrm{p}=$ o.oo6), while those with lower the years of service have higher levels of personal satisfaction. In terms of shift work there were not found statistically significant correlation compared to other socio-demographic characteristics, professional burnout or quality of life. There is a strong negative high statistical correlation 
between the professional burnout and mental quality of life of components ( $\mathrm{r}$ $=-0.479 ; \mathrm{p}<0.001$ ), while subjects with diagnosed higher level of professional burnout have a significantly lower quality of mental health.

\section{Discussion}

The largest number of respondents ( $83 \%)$ is exposed to stress at work in our research and professional burnout syndrome was observed in $42.6 \%$ of workers. In more than half of the respondents is registered a high level of common mental components of health, and social functioning is also significantly higher in patients without the presence of the syndrome while differences from the domain of physical functioning, vitality, mental health, general health, body pains and limitations due to physical health were not found. According to the World Health Organization (1996), every person has the right to a safe workplace and a healthy environment that allow for a normal social and productive life. Therefore, the external and internal factors have a significant role in explaining the quality of life which has been confirmed by numerous studies. Quality of life is a psychological construct, which does not arise automatically from satisfying basic needs, but from the whole psychological structure of the individual interacting with the physical and social environment in which he lives (Taillefer, 2003). Felce and Perry (1995) define quality of life as an overall general well-being, which includes objective factors and subjective evaluation of physical, material, social and emotional well-being, including personal development and meaningful activity (Felce and Perry, 1995). According to members of the International Well Being Group's quality of life is multidimensional term, which is made of: standard of living, health, productivity, the possibility of achieving close contact, security, belonging to the community and a sense of security in the future (World Health Organisation, 1996). Many studies have shown that the psychological state of anxiety and depression in particular, appear as mediators of health outcomes and subjective quality of life in situations of illness (Costa and McCrae, 1980).

In similar studies results of our study were significantly better than the results of a study conducted in Chile (Andrades and Valenyuela, 2007), but lower compared to the results of a study conducted in Turkey (Cinnamon, 2003). By analysing the questionnaire, SF-36 the presence of burnout syndrome is found among the respondents, particularly with regard to domain limitations due to emotional problems, social functioning and physical functioning. As for the common components of physical and mental health, the difference compared to the PCS was not observed, while the difference between the groups of patients for the presence of syndrome professional burnout highly statistically significant, and mental health of the respondents is at a significantly higher level in the group without the presence of the syndrome. Experiencing positive emotions at work is considered an important part of nursing professional life, and has a significant impact on patient safety, quality of service, commitment and stay in the organization and the profession. Numerous studies point 
out those experiencing positive emotions is an important part of nursing professional life, and has a significant impact on the quality of services provided. Positive emotions at work are associated with better health, a higher degree of job satisfaction, responsible behaviour at work, higher work performance and quality of work, greater resistance to stress and burnout, rarely changes of jobs, better relations with other people, desirable behaviour and thoughts and lower incidence of divorce (Golubic and Mustajbegović, 2011). The results of longitudinal Next study from 11 European countries showed that in all countries there is a significant degree of psychological exhaustion of nursing staff, particularly in Slovakia and Germany where they registered the highest scores of negative effects (Stourdeur et al., 2003).

The disease is undoubtedly one of the external factors that negatively affect the quality of life of the individual. It can be said that the impact of disease on quality of life is multidimensional. The disease not only affects in terms of physical symptoms and thereby interferes with the function, but also there are present indirect effects such as changes in work capacity, decrease in the quality health care, potential isolation, increasing dependence on others, bad habits and so on (Hasselkorm, 2005).

Our research has shown that older people are more exposed to work related burnout and depersonalization; younger people have a higher quality of mental and physical health, while those with higher values of years of service have a greater value on the MBI scale. Strong negative high statistically significant correlation was found between professional burnout and mental components of quality of life. Higher levels of professional burnout have subjects who have a significantly lower quality of mental health. Professional burnout syndrome is more than stress conditioned by professional activities; he indicates a state of complete physical and emotional exhaustion caused by excessive and futile efforts at work. Studies conducted in Finland and Sweden show that the burnout syndrome is more expressed with women older than 50 years and that work in none productive sectors. Job satisfaction is considered to be relatively persistent phenomenon that involves affective orientation factors of the working environment. Job satisfaction is an important factor of success at work. Unsatisfied people transferred their dissatisfaction with the team members and to service users, and in the case of health care workers, to patients. With a decrease in job satisfaction it's also reduced a sense of personal success (achievement). Dimension perception of reduced personal success involves reducing the feelings of competence and achievement at work (Thiruchelvi and Supriya, 2012).

\section{Conclusions}

In our study, more than half of respondents (83\%) are exposed to stress at work, while the professional burnout syndrome was detected in $42.6 \%$ of respondents. Between professional stress and work experience and MBI result, there 
is a significant correlation. Respondents who have professional burnout syndrome have a lower level of quality of life.

\section{References}

ANDRADES BARRIENTIOS, L. and VALENZUELA SUAZO, S., 2007. Quality of life associated factors in Chileans hospitals nurses. Revista Latino-Americana de Enfermagem, vol. 15, no. 3, pp. 480-486.

CIMETE, G., GENCALP, N.S. and KESKIN, G., 2003.Quality of life and job satisfaction of nurses. Journal of Nursing Care Quality, vol. 18, no. 4, pp.151-158.

COSTA P.T. and MCCRAE R.R. 1980. Influence of extraversion and neuroticism on subjective well-being: Happy and unhappy people. Journal of Personality and Social Psychology, no.38, no.4, pp. 665-678.

FELCE, R. and PERRY, J., 1995. Quality of life: Its definition and measurement. Research in Developmental Disabilities, vol.16, no.1, pp.51-74.

GOLUBIĆ, Rand MUSTAJBEGOVIĆ, J. 2011. Kvalitet života zdravstvenih djelatnika. In: Vuletić, G. Kvaliteta života I zdravlje. Osijek: Hrvatska naklada za znanost, pp. 220 - 228. [viewed 10 June 2017]. Available from: https://bib.irb.hr/datoteka/592441.KVALITETA_IVOTA_I_ZDRAVLJE. pdf.

HASSELHORM, H.M., MUELLER, B.H., TACKENBERG, P. and BUESCHER A., 2005.Psychological and physical health among nurses in Europe. NEXT scientific report. University of Wuppertal and University of Witten, Germany, pp. 35-37. [viewed 10 June 2017] .Availablefrom:https:// www.econbiz.de/archiv1/2008/53604_lifting_bending_tasks.pdf

JACSON, S.H., 1999. The role of stress in anaesthetists' health and well-being. Acta anaesthesiologica Scandinavica, vol. 43, no.6, pp. 583-602.

MASLACH C, JACKSON S.J., LEITER M.P. 1996. .Maslach Burnout Inventory Manual. Mountain View, California: CPP.

NYSSEN AS, HANSEZ I, BAELE P, LAMY M and DE KEYSER V., 2003. Occupational stress and burnout in anaesthesia. British Journal of Anaesthesia,vol.9o, no.3, pp.333-337.

STOURDEUR, S., D'HOOPRE, W., VAN DERHEIJDEN, B., DIBISCEGLIEMLAINE, M., VAN DER SCHOOT, E. and the NEXT-Study Group, 2003. Leadership, job satisfaction and nurses' commitment. Working conditions and intent to leave the profession among nursing staff in Europe. National institute for working life, Stockholm. [viewed 10 June 2017]. Available from: http://www.hosp.ucl.ac.be/recherche/LeaderCommitm.pdf

TAILLEFER, M.-C., DUPUIS, G., ROBERGE, M.A., LEMAY, S. 2003.Health-related quality of life models: Systematic review of the literature. Social Indicators Research, vol. 64, no.2, pp. 293-323. 
TENNAT C., 2001. Work-related stress and depressive disorders. Journal of psychosomatic research, vol. 51, no.5, pp. 697-704.

THIRUCHELVI, A. and SUPRIYA, M.V., 2012.An investigation on the mediating role of coping strategies on locus of control wellbeing relationship. The Spanish Journal of Psychology, iss.15, no.1, pp. 156-165.

WARE J.E., 1993.SF-36 Health Survey: Manual interpretation guide. Boston, MA: The Health Institute. New England Medical Center.

WORLD HEALTH ORGANIZATION, 1996. Programme on mental health. WHOQOL-BREF Introduction, administration, scoring and generic version of the assessment. Field Trial Version. 